$06 ; 13$

\title{
Анализ структуры многослойных нанокристаллических покрытий на основе параметров массопереноса плазмы, вычисленных методом Монте-Карло
}

\author{
(C) А.В. Черногор, И.В. Блинков, Д.С. Белов, В.С. Сергевнин, А.О. Волхонский
}

Национальный исследовательский технологический университет „МИСиС“, Москва, Россия

E-mail: avchernogor@gmail.com

Поступило в Редакцию 29 октября 2018 г.

\begin{abstract}
Представлены результаты моделирования плазменных потоков на поверхность вращающихся подложек при горении вакуумной дуги катодной системы $\mathrm{Cr}-\mathrm{Ti}-\mathrm{Mo}$. Экспериментально исследованы структура и состав arc-PVD-покрытий $\mathrm{Ti}_{0.15} \mathrm{Cr}_{0.74} \mathrm{Mo}_{0.11} \mathrm{~N}_{0.84}$. Проведен анализ результатов численного моделирования структуры покрытий на основе данных, полученных экспериментальным путем. Показана возможность моделирования структуры многослойных, многокомпонентных покрытий и концентрационного распределения химических элементов, его составляющих, с помощью расчета плазменных потоков методом Монте-Карло.
\end{abstract}

DOI: 10.21883/PJTF.2019.03.47265.17575

Многослойные покрытия нашли широкое применение в различных областях промышленности, что обусловлено их уникальными физическими и механическими свойствами [1-4]. Слоистая структура покрытий позволяет реализовать в них свойства, адаптивные к различным условиям эксплуатации $[5,6]$. В частности, в случае износостойких покрытий это проявляется в сочетании слоев с высокой твердостью $(\mathrm{CrN}, \mathrm{TiN}, \mathrm{ZrN})$ и слоев, характеризующихся низким коэффициентом трения самого материала или продуктов его окисления в дорожке трения [7]. Свойства таких покрытий чувствительны к параметрам структуры $[8,9]$, а с учетом того, что их толщина составляет величину порядка нескольких нанометров, их изучение осложнено особенностями методов анализа. Повсеместно для изучения распределения элементов в таких покрытиях применяются методы ожеспектроскопии и рентгеновской фотоэлектронной спектроскопии (РФЭС), глубина анализа которых составляет от нескольких десятков атомных слоев до $5 \mathrm{~nm}$ в зависимости от материала покрытия. Все это приводит к тому, что при изучении многослойных наноструктурных покрытий с периодом модуляции меньше указанного выше сбор информации происходит не только с изучаемого поверхностного слоя, но и с нижележащих слоев, тем самым увеличивается неопределенность при исследовании элементного состава отдельно взятого слоя.

В настоящей работе предложена стохастическая модель Монте-Карло расчета плазменных потоков, формирующих многослойное покрытие и определяющих характерное концентрационное распределение химических элементов, его составляющих, в каждом слое. Адекватность данной модели проверялась сопоставлением расчетных концентрационных профилей с экспериментальными данными для толщин сформированных слоев, полученными с использованием просвечивающей микроскопии высокого разрешения, и анализом элементного состава, определенного по всей глубине покрытия методом РФЭС. В качестве материала покрытий бы- ла выбрана многокомпонентная система $\mathrm{Ti}-\mathrm{Cr}-\mathrm{Mo}-\mathrm{N}$, которая характеризуется формированием ГЦК-твердых растворов нитридов титана, молибдена и хрома с полной неограниченной растворимостью.

Методом вакуумно-дугового осаждения (arc-PVD) на установке (рис. $1, a)$, оборудованной тремя испарителями, были приготовлены покрытия $\mathrm{Ti}_{0.15} \mathrm{Cr}_{0.74} \mathrm{Mo}_{0.11} \mathrm{~N}_{0.84}$ при потенциале смещения $U=-120 \mathrm{~V}$. Титан и молибден наносились путем испарения катодов из сплавов ВТ1 и Мо через магнитные сепараторы, что предотвращало попадание капельной фазы, образующейся при испарении катодов, в структуру формируемых покрытий.

В результате планетарного вращения подложек при одном полном обороте вокруг оси столика образуется слой, состоящий из субслоев толщиной несколько нанометров. Поскольку структура покрытия формируется последовательным наложением данных слоев, численное интегрирование плазменных потоков проводилось только для одного такого слоя. Расчет массопереноса плазмы осуществлялся согласно модели, представленной ранее в работе [10]. Начальное положение ионов, их заряд, энергия и вектор скорости генерировались случайным образом так, чтобы распределения значений данных величин соответствовали литературным и экспериментальным данным [11-14]. В предложенной модели учитывалось только упругое взаимодействие, так как вклад неупругих столкновений в диссипацию энергии ионов незначителен [15]. С учетом геометрических параметров камеры вакуумно-дуговой установки среднее время пролета иона из катодного пятна до поверхности подложек составляет порядка $10^{-4} \mathrm{~s}$, что также позволяет не учитывать рекомбинационные процессы [15]. Для расчета длины свободного пробега и угла рассеяния ионов на атомах газа использовался модифицированный потенциал Борна-Майера в приближении квазижестких сфер, представленный в работе [16].

В качестве входных параметров для расчета задавались парциальное давление азота и аргона в камере, 

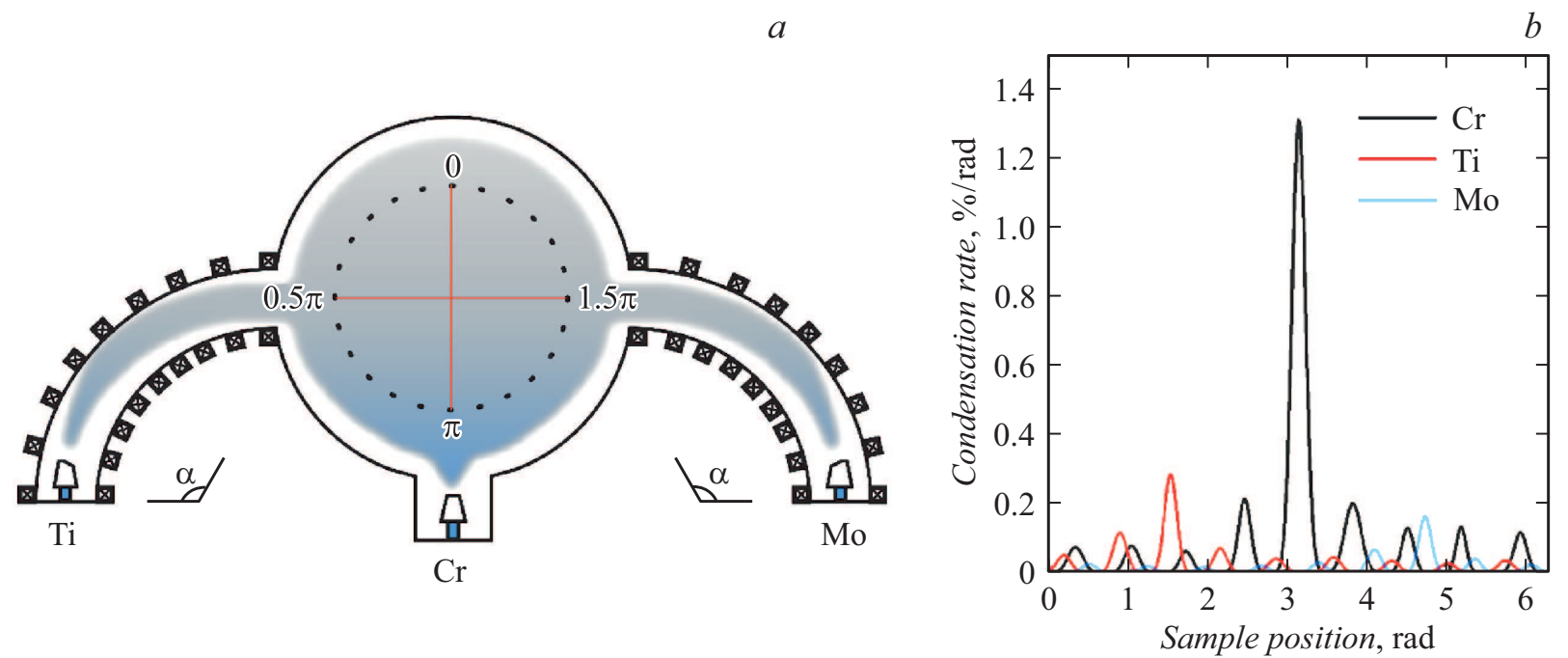

Рис. 1. Схематичное изображение камеры $(a)$ и зависимость концентрации плазменных потоков на поверхность подложек от их положения внутри камеры в координатах подложкодержателя $(b)$.

равное 0.4 и 0.8 Ра соответственно, геометрические параметры магнитных катушек сепараторов (50 витков, угол разворота тора $\alpha=120^{\circ}$, сила тока $\left.I=13 \mathrm{~A}\right)$ и прямоточного испарителя, а также экспериментальные данные о распределении ионов молибдена, титана и хрома по энергиям и зарядам, представленные в работах [8-11]. Для каждого материала катода процесс массопереноса ионов от поверхности катода до поверхности подложек рассчитывался путем интегрирования одного миллиона частиц.

Поскольку форма концентрационных пиков плазменного потока не зависит от абсолютных значений его плотности, профили, рассчитанные методом МонтеКарло, приводились к экспериментальным значениям концентраций элементов в покрытии. На рис. $1, b$ представлены результаты расчетов плазменных потоков на поверхность подложек в зависимости от их положения в камере в координатах вращающегося столика. Площадь под представленными кривыми соответствует концентрациям элементов в покрытии, полученным методом энергодисперсионной рентгеновской спектроскопии, т.е. эти данные отражают относительную скорость осаждения элементов на каждом участке вращения подложек.

Видно, что планетарное вращение подложек с отношением скорости вращения вокруг оси подложкодержателя к скорости вращения вокруг оси столика 1:9 на всех профилях приводит к формированию девяти пиков с максимальной концентрацией в области, отвечающей наименьшему расстоянию между подложками и соответствующим испарителем. При этом для профилей молибдена и титана наблюдается асимметрия данных пиков, которая вызвана концентрацией магнитных полей возле внутренней стенки криволинейного фильтра.

Согласно расчетам, более 58\% плазменного потока, генерируемого горением Cr-катода, приходится на концентрационный пик с наибольшей интенсивностью, соответствующий наименьшему расстоянию между подложками и Сr-катодом. Для плазменных потоков титана и молибдена данные величины составляют около $39 \%$. Различия в распределении плазменной компоненты вакуумной дуги в камере вызваны узкой фокусировкой плазменного потока прямоточного испарителя, в то время как для испарителей, оборудованных сепараторами, за фокусировку ответственны катушки самого сепаратора, которые не позволяют сузить угол разлета плазменного потока на выходе из сепаратора.

Приготовление покрытий для изучения их структуры осуществлялось путем изготовления ламелей поперечного сечения на поверхности покрытия с их фиксацией на сетке для просвечивающего электронного микроскопа (ПЭМ) с последующим вырезанием тонкого окна методом фокусируемого ионного пучка. Согласно полученным изображениям ПЭМ (рис. 2,a), покрытия характеризуются слоистой структурой, состоящей из шести темных субслоев толщиной до $4 \mathrm{~nm}$ и одного светлого субслоя толщиной порядка $26 \pm 2 \mathrm{~nm}$. Совокупность данных субслоев составляет один слой толщиной порядка $43 \pm 4 \mathrm{~nm}$, сформированный в процессе одного полного цикла вращения подложки вокруг оси столика $(0-2 \pi$ в координатах столика). Результаты модельных расчетов, представленных на рис. $2, b$, хорошо согласуются с экспериментальными данными. При этом, согласно расчетам, толщина субслоев, сформированных в области прохождения подложек через три пика с наибольшей интенсивностью для хрома, составляет порядка $24 \mathrm{~nm}$, что соответствует размерам характерных областей в полученных покрытиях.

На рис. 3, $a$ представлено распределение элементов по толщине покрытия, полученное методом РФЭС с послойным травлением. Видно, что, несмотря на многослойную структуру покрытий, профили характеризуются волнообразным распределением элементов без выражен- 

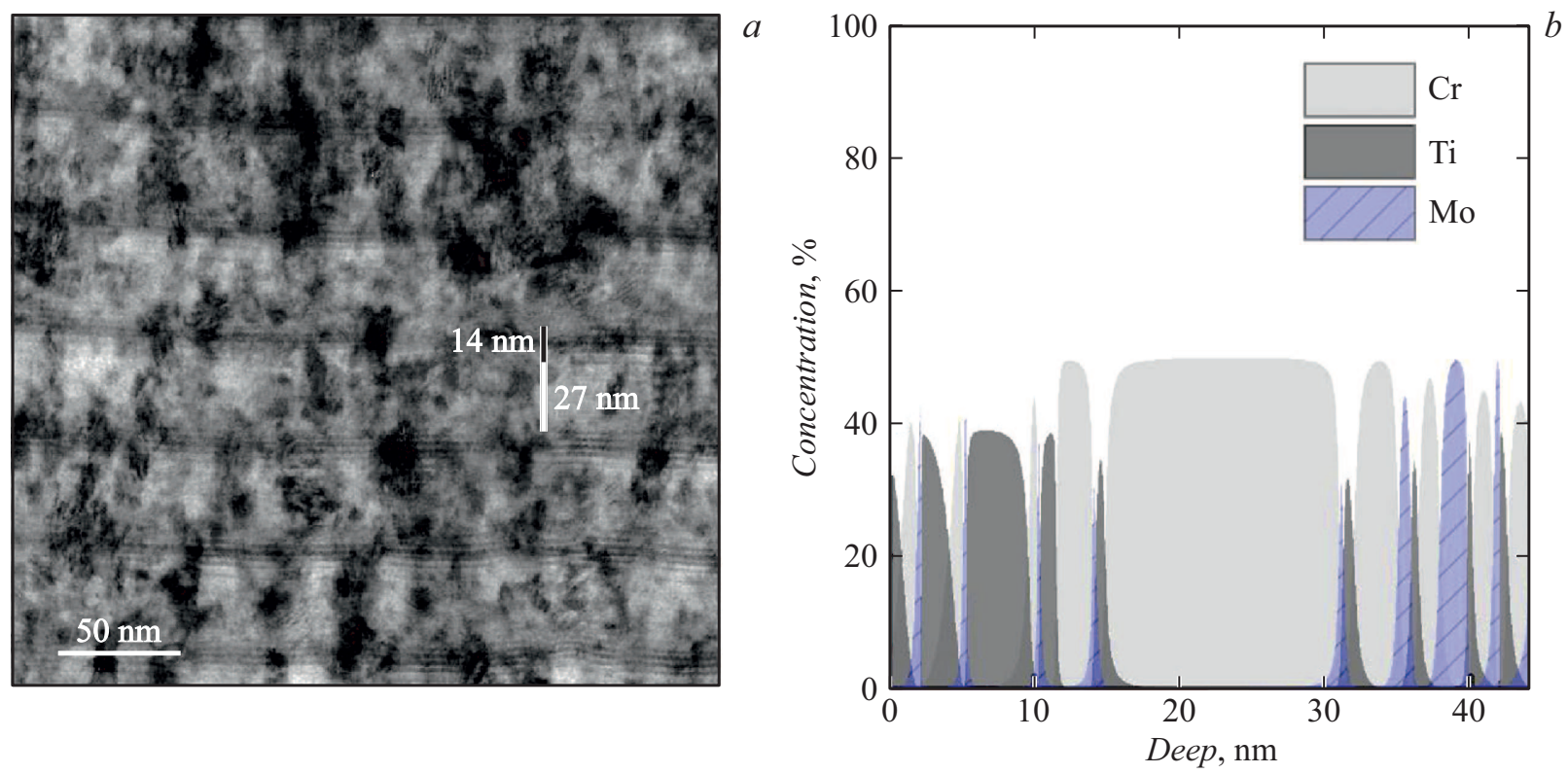

Рис. 2. Изображение ПЭМ поперечного сечения покрытия $\mathrm{Ti}_{0.15} \mathrm{Cr}_{0.74} \mathrm{Mo}_{0.11} \mathrm{~N}_{0.84}(a)$ и модель структуры покрытия при толщине слоя $42 \mathrm{~nm}$ согласно полученным расчетам $(b)$.
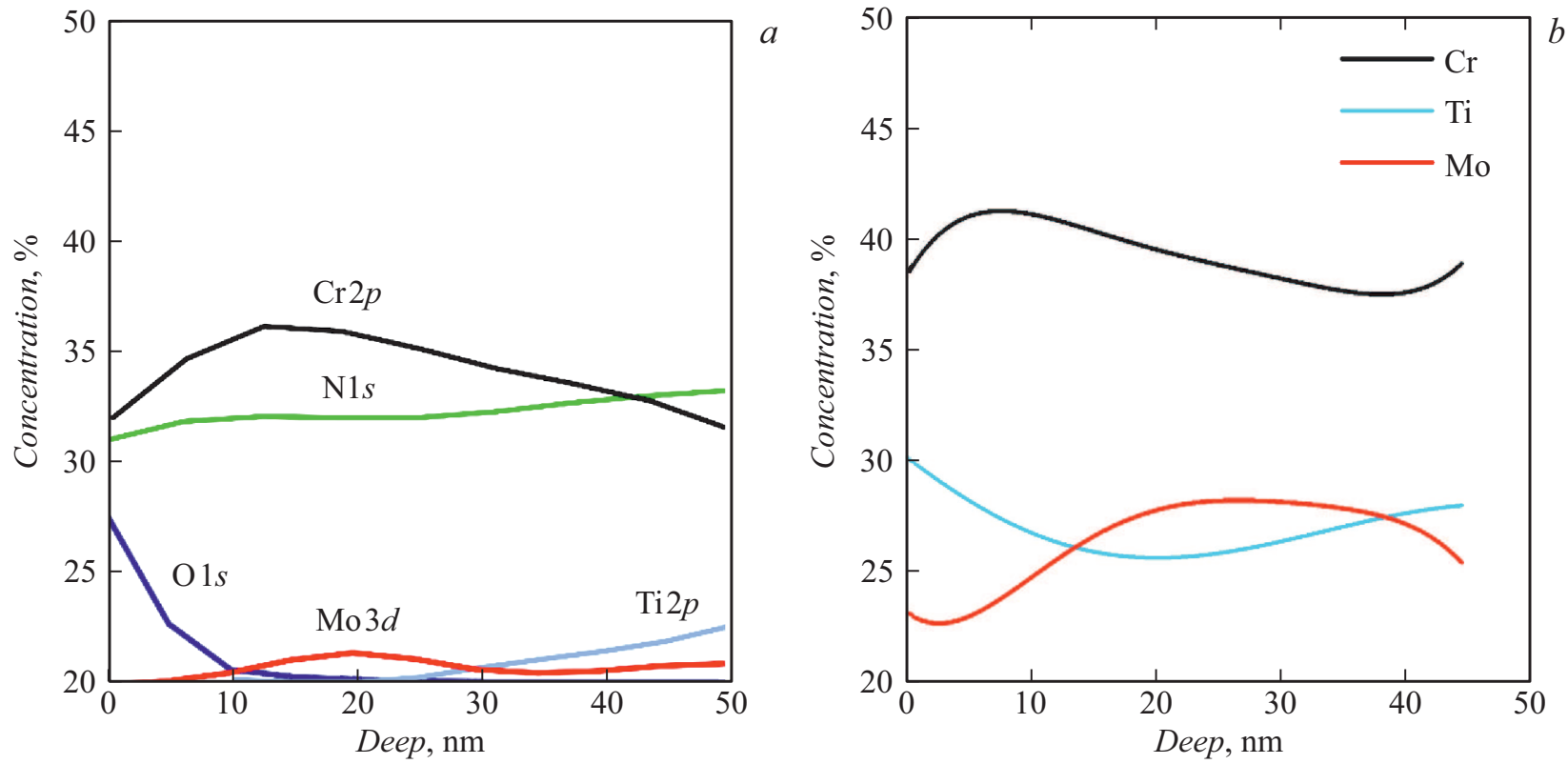

Рис. 3. Распределение элементов по глубине покрытия, полученное методом РФЭС с послойным травлением (a), и результаты численного интегрирования с поправкой на глубину выхода сигнала $5 \mathrm{~nm}(b)$.

ных границ раздела между слоями и отсутствием пиков, которые отвечают субслоям. По всей вероятности, это вызвано глубиной анализа РФЭС, которая, как правило, лежит в интервале от 3 до $5 \mathrm{~nm}$. Это предположение подтверждается модельными расчетами (рис. $3, b$ ), которые были обработаны с учетом глубины анализа $5 \mathrm{~nm}$. Видно, что в данном случае происходит сглаживание концентрационных пиков в характерные волнообразные распределения с формированием областей, обогащенных хромом, титаном и молибденом. При этом отсутствует какая-либо связь этих профилей с многослойной структурой покрытий, наблюдаемой на снимках ПЭМ (рис. 2), т.е. только на основе данных РФЭС сложно сделать вывод о распределении элементов по глубине покрытия со слоями толщиной порядка несколько нанометров.

Таким образом, в работе показано, что изучение покрытий на основе данных, полученных только экспериментальным путем, не дает полного представления о структуре многослойных многокомпонентных покрытий. При этом в результате того, что глубина анализа дан- 
ных методом РФЭС соизмерима с толщиной отдельных субслоев, возникают сложности при описании распределения элементов по глубине покрытий. Представленная стохастическая модель формирования слоистой структуры покрытий путем расчета плазменных потоков, формируемых в результате горения вакуумной дуги, использующая в качестве входных параметров физические постоянные материалов катодов (распределения энергий и зарядов ионов катодной дуги, радиус и массу атомов), давление реакционной среды и параметры магнитных полей испарителей, дает возможность оценить характерное распределение химических элементов, содержащихся в каждом из субслоев многослойного покрытия.

Работа выполнена при финансовой поддержке РФФИ в рамках проекта № 18-32- 00372 (мол_а).

\section{Список литературы}

[1] Akbarzadeh M., Shafyei A., Salimijazi H.R. // Int. J. Eng. Trans. A: Basics. 2014. V. 27. N 7. P. 1127-1132.

[2] Sergevnin V.S., Blinkov I.V., Belov D.S., Volkhonskiy A.O., Skryleva E.A., Chernogor A.V. // Inorg. Mater. 2016. V. 52. N 7. P. 735-742.

[3] Nohava J., Dessarzin P., Karvankova P., Morstein M. // Tribol. Int. (Elsevier). 2015. V. 81. P. 231-239.

[4] Вольпяс В.А., Тумаркин А.В., Михайлов А.К., Козырев А.Б., Платонов Р.А. // Письма в ЖТФ. 2016. Т. 42. B. 14. C. $87-93$.

[5] Блинков И.В., Черногор А.В., Волхонский А.О., Сергевнин В.С., Белов Д.С., Саргаева О.Н. // Неорган. материалы. 2017. Т. 53. № 1. Р. 105-114.

[6] Береснев В.М., Соболь О.В., Погребняк А.Д., Гранкин С.С., Столбовой В.А., Турбин П.В., Мейлехов А.А., Арсеенко М.Ю. // Письма в ЖТФ. 2016. Т. 42. В. 10. С. 70 77.

[7] Inspektor A., Salvador P.A. // Surf. Coat. Technol. 2014. V. 257. P. $138-153$.

[8] Погребняк А.Д., Береснев В.М., Бондар O.B., Abadias G., Chartier P., Постольный Б.А., Андреев А.А., Соболь О.В. // Письма в ЖТФ. 2014. Т. 40. В. 5. С. 59-66.

[9] Соболь О.В., Мейлехов А.А. // Письма в ЖТФ. 2018. Т. 44. B. 2. C. $56-64$.

[10] Chernogor A., Blinkov I., Volkhonskiy A. // Int. J. Comput. Phys. Ser. 2018. V. 1. P. 30-34. DOI: 10.29167/A1I1P30-34

[11] Eriksson A.O., Zhirkov I., Dahlqvist M., Jensen J., Hultman L., Rosen J. // J. Appl. Phys. 2013. V. 113. N 16. P. 163304.

[12] Zhirkov I., Eriksson A.O., Petruhins A., Dahlqvist M., Ingason A.S., Rosen J. // J. Appl. Phys. 2014. V. 115. N 12. P. 123301.

[13] Zhirkov I., Eriksson A.O. // J. Appl. Phys. 2013. V. 114. N 21. P. 213302

[14] Месяи, Г.А., Баренгольи С.А. // УФН. 2002. Т. 172. № 10. C. $1113-1130$.

[15] Барвинок В.А., Богданович В.И. Физические основы и математическое моделирование процессов вакуумного ионно-плазменного напыления. М.: Машиностроение, 1999. $309 \mathrm{c}$.

[16] Вольпяс В.А., Гольман Е.К. // ЖТФ. 2000. Т. 70. В. 3. C. $13-18$. 